\title{
The Impact of Censorship on the 'Historical' Video-Game
}

James Andrew John Piggott, Department of History, University of Warwick, Coventry

\section{Abstract}

This article presents two related ideas. Firstly, video-games should be considered a historically relevant medium through their capacity to generate narratives and lessons of the past. Secondly, the issue of censorship - the doctoring of the past when creating said narratives - is as equally detrimental to history as shown within video-games as it is in alternative formats. The historical significance of censorship within video-games, however, has been largely ignored, mainly due to the perceived 'trivial' or 'ludified' nature of the medium. As a result, the historiographical capacity of video-games continues to be trivialised and undermined. These arguments are covered over three sections. The first unpacks several criticisms of video-games, in turn showing the medium's historical capacity. The second uses the example of Nazism to describe and explain the presence of censorship within video-games and the rationale that informs it. The final section links these two ideas, discussing the historical impact of censorship within video-games and why the 'ludic frame' of video-games seemingly shadows their equally significant 'historical frame'.

Keywords: Video-games, censorship in video-games, historical video-games, framing in video-games, ludic meaning of video-games, translating history into informatics

\section{Introduction}

A series of searches and link-following landed me on the article that inspired this piece. The article 'Here's how Wolfenstein 2 censored that Hitler scene for the German release' (Good, 2017) described the admittedly crude attempts of censoring Hitler in the video-game Wolfenstein II: The New Colossus (MachineGames, 2017). Scrolling down, I came across a comment thread between Ollie72 and AmiralPatate. They - in a surprisingly civilised way for internet standards - debated whether this censorship was right, with Ollie72 viewing that no 'fun' should ever be associated with Nazism, hence justifying the changes; AmiralPatate, on the other hand, viewed it as wholly inappropriate, being counterproductive to the ideas it tries to hide. It dawned on me 
how alien such a discussion would have seemed 30 years ago, considering what core theme this anonymous duo are really debating: the relationship between history and video-games - specifically, whether the censorship of history is relevant in the videogame medium, whether it is 'acceptable'. This article views censorship to be the intentional suppression of content considered obscene, unacceptable or dangerous by the censor (Oxford Living Dictionaries, n.d.). Under this definition, censorship is as present in video-games as in any other media format. Ollie72 and AmiralPatate are discussing genuine censorship. This article will argue that this matters: that the censorship of themes and ideas in video-games is as detrimental to our access and understanding history as it would be in any alternative format. With the video-game industry only growing in both size and complexity, so will the types of narratives and histories that they recreate. It is crucial that our understanding of video-games as a historical medium moves alongside these trends.

\section{Video-games as a historical format}

This discussion only has urgency if video-games are considered historically relevant. That being said, video-games are as capable of presenting a curated narrative of the past from which meaning and understanding can be ascertained as any other common historical formats. In demonstrating this idea, three criticisms will be challenged. Each criticism focuses on a different characteristic of video-games that, on the surface, may appear to detrimentally serve their historical function and impair historical insight.

But is this just what historical video-games are: a form of historical fiction? In dissecting some criticisms, it becomes clear that this is not the case; that, instead, video-games are historically relevant beyond their historical appearance.

The first criticism, presented by Alexander Galloway, argues that video-games constitute the 'absence of history': through translating history into informatics computer algorithms, formulas, code - the 'diachronic details of lived life' that embodies history are lost (Galloway, 2006: 103). The conversion of historical themes identities, politics, economics - into game-compliant information, leaves just that: information, digitised and drained of historical essence, an 'entirely codified affair within the logic of software' (Galloway: 102). Informatics cannot represent history as they are devoid of 'both meaning and the encoding of meaning in material form': the meaning of video-games is in the act of play, in traversing and optimising the presented informatics in order to win (Galloway: 104). No independent historical meaning can be extracted when history is so considerably disfigured. 
In arguing this position, Galloway touches on a key epistemological question of history: can we truly access it? For Galloway, video-games do not access history: we are accessing a codified, artificial reconstruction of historical reality, distanced by its menus and options. We cannot obtain a historical meaning from it as we have never accessed history in the process. Adam Chapman - a founding figure of historical video-games studies - sees Galloway's perspective as symptomatic of a wider historiographical misconception: that accessing history is equivalent to accessing the past (Chapman, 2013: 320). The past cannot be accessed; we cannot physically relive events objectively as they occurred. As such, we must mediate such events through history - the act of forming particular representations or conceptions of said past: how it happened, why it happened, the consequences of it happening, and so on. Traditional historical formats exhibit this process, with historians formulating - based on personal interpretations of given past events - curated narratives of the past. The conversion of the past to these narratives, to words on a page, are no different to the video-game designer's translation of the past to a particular set of code. Like the traditional historian, the video-game designer makes conscious, subjective choices regarding how their historical interpretation is crafted: what is and is not included, deciding emphasis, choosing the order of play. As such, for Galloway to argue that video-games cannot constitute 'history', due to their abstraction of the past into code, he must also accept the futility of all historical formats as well as, more generally, the inability to ever tap into the past full-stop.

Video-games' 'informatics' do not constitute the absence of history, but are history themselves. What code is to a video-game designer is what words are to a written historian: it is through them that we access the past and ascertain a particular understanding of it. Galloway's notion that meaning can only be attributed to the tackling of a game's informatics now appears far removed. We do not find meaning in the physical process of reading words off a page; we find meaning in what these words suggest, argue and conjure in our minds. Relatedly, meaning in video-games emerges from how these informatics present digitised historical worlds and how they permit us to interact with it.

Chapman provides a clear example of this informatics-meaning relationship: 'modding' (Chapman, 2013: 317). Modding is the process whereby individuals, independent of the game designers, modify, add or remove aspects of a game for a particular purpose. Common modifications of historically based video-games seek to 'better reflect' the realities of history the game claims to represent (say, making a historical faction's unique powers more representative of their 'actual' strengths in the 
past). If, as Galloway suggests, no historical meaning is ever extracted from videogames, there would be no demand for such historically orientated modding. If gamers only cared for the informatics themselves, modifications would solely focus on optimising and bettering the informatics for their own sake; the tweaking of their historical veneer would be unnecessary. The ability for a modification of a game's content to change its conjured historical narrative demonstrates video-games' capacity to create historical meaning.

Referring back to the raised epistemological question, therefore, video-games enable us to access history to the same extent that any other historical medium does; as Chapman says, 'The fact that in (video-games) this is done through algorithm instead of words is [...] of little consequence' (2013: 324). The importance of censorship in video-games becomes apparent from this mind-set; the consequences of eradicating or altering certain informatics have the same impact on our access to history as in alternative mediums. Censorship means we access a different history to what we would have otherwise; it generates different impressions and alters our understanding of how history and the past can relate.

Clyde, Hopkins and Wilkinson understand Galloway's 'informatics' differently: it is not the conversion of history into informatics that depletes their historical relevance, rather our interaction with said informatics. Games 'fail to be history because of the nature of player interaction with them and what they allow the player to do' (Clyde et al., 2012: 9). It is in this interactive element that 'counter-factuals' emerge: narratives and sequences that go against the historical canon. In essence, the agency inherent to video-games runs counter to the nature of history: history, unlike in video-games, is 'not variable in the sense that player effort can change it in pursuit of a win state, such as a preferred past (Clyde et al.: 10). Alternate histories 'tell us little about history' (Clyde et al.: 11). Clyde, Hopkins and Wilkinson take a more purely historiographical perspective on video-games compared to Galloway: video-games are not historical, neither adhering to nor demonstrating the fundamental principles of history.

Yet Clyde, Hopkins and Wilkinson seemingly fall into the same trap as Galloway: historically based video-games, by their nature of presenting a particular narrative on the past, are historical. They may not adhere to the 'traditional' principles of historiographical practice that the authors believe they should, but they still provide us with historical understanding. For one, the existence of agency in video-games demonstrates the role of decisions and causality throughout history (Elliot and Kapell, 2013). Historical games often pit players in choice-determinate scenarios in which the 
slightest change can have far-reaching consequences for both the narrative and the player's gameplay experience (for example, in the Sid Meier's Civilisation franchise: deciding whether to play in an aggressive, expansionistic manner or a defensive, diplomatic one, and seeing the results manifest). Video-games, as such, provide an accessible avenue for appreciating the logic that underlies history and its arguments. More than exclusively presenting an explicit argument via their informatics and constructed narrative - as Clyde, Hopkins and Wilkinson would seem to prefer - the very nature of gameplay affords video-games a unique ability to live the mechanisms of history. Video-games teach us what history is about. The importance of censorship becomes apparent here: what historical lessons do video-games espouse when their content is so easily morphed and tweaked for an agenda?

Brian Rejack - my final critic - also touches on the potential lessons that historical video-games can provide. For Rejack, the capacity for video-games to historical meaning is hindered by their (current) technical limitations (Rejack, 2007). Videogames, while proposing themselves to be 'historical simulations' of past events, cannot provide the level of 'historical insight' of, say, physical historical re-enactment (which is rooted 'in the body') (Rejack: 412). This is because of the technical and playability sacrifices video-games must inevitably make. Rejack raises two examples: revive abilities (i.e. the ability for both the player and his team-mates to come back to life) and limited AI interaction (i.e. how interaction with in-game characters is often very controlled, limited to a set number of unvarying dialogue options and scripted events). Both of these distance the player from the constructed world's supposed 'realism'. Only when these hurdles are overcome can 'emotional engagement and the potential for revision and reflection' become possible (Rejack: 422).

Rejack's criticisms are based on the assumption that historical video-games are designed for the sake of re-enactment: that through them, we are not just understanding the past, but physically reliving its experiences via realistic environments and empathetic engagements. Historical video-games are more varied in intention than this. They can be more broadly categorised into 'simulations', which fix players into a historically prescribed master narrative - that the player experiences passively, unable to create consequential 'counter-factuals' - and 'theoretical' games, where the player is granted an assortment of historical assets from which they create their own historically flavoured narratives (Uricchio, 2005). To criticise video-games for not creating meaningful historical engagement because of failed re-enactment means the same criticisms should be levelled at other mediums. Do books fail to provide historical insight due to their entirely linear, predetermined nature? Their 
continued creation suggests otherwise. Historical 'engagement' is not wholly determinate on the extent of physical interaction and 'realism' within one's medium. Video-games need not be constrained to the realms of reality in order for us to glean some historical message and understanding - the ability for video-games to 'transcend' reality, engaging in ideas and procedures that the contemporary historical actor could not have appreciated at the time, is where this capacity lies. As mentioned, video-games can explore wider ideas of historical causality, providing an appreciation of complex interactions between civilisations by placing the player above a singular perspective. When considering censorship, therefore, its impact should not be entirely weighed on how far its presence affects our physical re-enactment of history (i.e. how it makes a game less 'accurate'). Instead, censorship should concern the lessons and narratives we ascertain from history.

Unpacking these criticisms makes the historical relevance of video-games clear: like all historically invested formats, video-games create deliberate historical narratives, each encouraging different understandings and impressions of the past. Their digitised nature is secondary to the stories they tell, while the agency they permit provides an unrivalled level of understanding behind how the past unravelled itself. As such, there is no reason to emphasise the importance of historical censorship in traditional formats while paying no attention to it in video-games: censorship has relevance in both, with the latter being woefully unappreciated.

\section{A case study: Censoring Nazism in video-games}

How Nazism has been censored in video-games serves as a good illustration of the beliefs that underlie video-game censorship. Nazism was chosen for several reasons. It is, arguably, the most common historical subject to face censorship in video-games (Miroweski, 2015). This seems logical considering that a sizeable portion of historical video-games are set during World War II (mostly in first-person-shooters, and in both turn-based and real-time strategy games). Furthermore, Nazism's legacy still reverberates today: how Nazism is understood still frames political discourse. In analysing its portrayal in video-games, we can better understand how said legacy is handled: how we wish to treat history and, specifically, how we want to handle our past's more troubling narratives. Video-games are a massive ever-growing media industry: in the UK, consumer spending on video-games rose to $£ 5.11 \mathrm{bn}$ in 2017 , up 12.4 per cent from 2016, with 32.4 million people playing games each year (Ukie, 2018). As the industry grows, the historical lessons shown through video-games will be consumed by a great proportion of the public. It seems necessary, therefore, to 
understand just what lessons the video-game industry is exerting and how this is affected through instances of censorship. Finally, this article focuses exclusively on historical censorship. Video-games have experienced just as much non-historically based censorship (O'Holleran, 2010) - for example, censoring violence and profanity but, based on the surveyed literature, discussions of historically based censorship are extremely limited in comparison.

When playing video-games containing Nazis or Nazism, players are likely not to see a swastika. Moreover, depending on the game's market and one's location, the player may not hear or read any Nazi-related references - for example, the word 'Nazi' itself, mentions of Hitler, or a 'Heil Hitler' salute, to name a few. More commonly, such references are censored in favour of alternative representations. In understanding why, two competing elements must be appreciated: the German criminal code and the nature of the gaming market. Germany has a long record of censoring video-games (Kain, 2012), but it is unique in its relationship to historical and political censorship due to a section of the Strafgesetzbuch (Criminal Code). $\$ 86$ and 86a, concerning the 'Dissemination of Means of Unconstitutional Organisations' and 'Use of Symbols of Unconstitutional Organisations', bans the production of material associated with a 'party which has been declared to be unconstitutional' (with 'National Socialist organisation[s]' being mentioned explicitly) including 'flags, insignia, uniforms, slogans and forms of greeting'. Hence, games containing Nazi-related material, which are then actively promoted and disseminated in Germany, have been subject to outright bans and costly legal proceedings.

A clause within $\$ 86$ permits the dissemination and use of said material if it is used 'to further civil enlightenment [...] to promote art or science [and] research or teaching'. Case no. 1 § 407-97, however, has set a legal precedence that has since excluded video-games as being such 'artistic' or 'teaching' material. The case saw the Local District Court of Frankfurt am Main accuse an individual of violating $§ 86$ through his disseminating copies of Wolfenstein $3 D$ - a first-person-shooter in which the player kills Nazis in various Nazi-themed locations, culminating in a battle with mechanised, minigun-laden Hitler. The individual appealed to the High District Court of Frankfurt, wherein the lower court's decision was upheld. The court argued that the use of Nazi material within the game environment was 'irrelevant', as 'such a use of prohibited symbols in computer games would be allowed it would hardly be possible to prevent an increasing use of such symbols in public', exposing more of the public to 'ideological manipulation by national socialist ideas' (obtained from Schwiddessen, 2018). 
This conclusion is significant is several regards. First, since the ruling, many game developers have made their games 'globally edited', removing all Nazi-related material as to save on the inevitable costly editing necessary for a release in Germany (Schwiddessen, 2018) - one of the world's largest gaming markets (Newzoo, 2018). Fewer have opted to produce a censored and non-censored version of their game, with the latter being 'geo-blocked' in Germany (i.e. forcing German consumers to buy the curated, censored version). In the German releases of the Wolfenstein series of games - all of which have centred around combating alternative-history Nazis - Nazism has been censored in numerous ways: in Wolfenstein II: The New Colossus, this included renaming the 'Nazis' to 'The Wolfs' or 'The Regime'; changing the swastika to a fictional symbol; removing Hitler's moustache, while also renaming him to 'Mein Kanzler' (as opposed to 'Mein Führer'), and, interestingly, removing references to the Holocaust (OpiumHerz, 2013). Similar artistic changes have been employed by other video-game developers in response to German requirements (OpiumHerz, 2013), meaning the exclusion of Nazism from video-games (especially by international, multi-market video-game companies) has - as of writing - become the norm.

It is important to note that the examples listed are from titles which are not explicitly seeking to be works of self-conscious historiography. Nevertheless, as historical expressions with the video-game format, they serve to indicate a second conclusion: the rationale and attitudes behind censorship and, subsequently, how history is affected. The argument - that the inclusion of Nazism naturalises and desensitises its existence - is interesting when compared with Nazism's treatment in films. Films, for the most part, are free to include Nazi imagery and themes as they fall under the category of 'art', which is exempt under $\$ 86$ (GameStar, 2016); Nazism within the film format does not, apparently, pose the same psychological dangers as when included in video-games. Video-games are not deemed equivalent to other mediums in their capacity for artistic, 'enlightening' expression; the format immediately discredits and devalues the ideas presented. If video-games are understood as an inherently trivialising medium when they draw on serious historical themes, there is little chance that this attitude will differ when they attempt to present works of history more intentionally. After all, if video-games risk 'manipulation' when they offer what is essentially historical fiction, they could be exceedingly more 'manipulative' when presenting a grounded piece of serious historiography.

Hence, the gaming process is understood as a trivialising process; a precedent prevails that sees heavy historical themes as morally incompatible with video-games. The relationship is muddied by the fact that, as argued, video-games can engage in 
historiography either passively, through having to (re)construct historical narratives, or more explicitly. The presence of this historiographical dimension questions the applicability behind the censorship's rationale. The notion of 'framing' will now be utilised in understanding censorship and history - specifically, that gaming constitutes an inappropriate 'frame' for history and, hence, is justifiably censored (Chapman and Linderoth, 2015: 149). What will be argued, however, is that the very process of censorships constitutes a more trivialising process than the game itself could ever be.

\section{Censorship and gaming}

] [A]n intrinsic effect of ludification, according to this view, is the trivialisation of the object of transformation' (Chapman and Linderoth, 2015: 143). Games inherently abstract real historical issues away from 'reality' through being games. Censoring sensitive historical elements, therefore, eliminates the possibility of such keying.

In understanding video-games as authentic historical mediums, however, the need to appreciate an additional frame becomes apparent: the game's 'historical frame'. Videogames, in harnessing available historical evidence, assemble and present a particular historical narrative, structured within the game's mechanisms for interactivity and agency. This can be done both 'automatically' - by the necessity to subjectively narrate the past when engaging in it - or explicitly and self-consciously, which is akin to conventional historiographical work. Censorship's impact on this frame is seemingly ignored. Through censorship, are we carelessly upkeying the very historical substance that is to be preserved? In other words, is historical integrity trivialised through censorship? I would argue yes. Censorship may protect historical elements from a video-game's 'ludic' influences - seemingly preventing them from being turned into Galloway's 'informatics' - but, in the process, the authenticity that one seeks to preserve is lost. In deciding to exclude information, a different historical narrative is crafted versus one where information was included; specifically, an argument that views the tweaking of the past for current agendas as acceptable. The historical frame of the video-game exerts a new meaning: it presents history as something malleable, something that the present can conveniently pick and choose from.

This discussion of censorship may appear tautological. Censorship is rarely viewed positively, especially when concerning 'traditional' historical formats (e.g. censorship in books or films). Yet video-games have only recently been viewed - by a portion of historians - as historically relevant formats, meaning the damage that censorship 
poses has not been truly appreciated. This position seems to derive from the precedent established by the Wolfenstein $3 D$ case: that video-games are incapable of 'civic enlightenment', neither as forms of 'teaching' or 'art'. Perhaps the ludic frame's acceptability only emerges when the video-game is considered to exhibit a wider message. As long as the historical frame is ignored, the spectrum of 'enlightening' messages video-games are deemed capable of exhibiting is limited. Video-games will continue to be understood primarily as an inherently risky engagement in historical issues, especially when it explicitly seeks to act as conventional historiography. With the acceptance of the historical relevance of video-games comes the acceptance of its 'ludic' nature; video-games are not separate from the history they attempt to exhibit, rather they can be part-and-parcel of it. Censorship becomes abhorrent when the historical frame is accepted: it belittles not just the video-games capacity as an art form, but also its interlinked historiographical capacity.

, 2018). This acceptance of the video-game format is growing, it seems. Video-games do not exist solely as informatised, digitised abstraction, but as a medium capable of 'enlightenment'. The ease at which these acceptances have unravelled themselves reiterates the importance of framing in understanding censorship. Once their 'artistic' - in this case, historical - frame is accepted, the once-trivialising perception of the game's ludic frame fades into irrelevance. The conversion of a historical argument into gameplay mechanisms and 'informatics' becomes an inherent mechanism of the medium, rather than constituting the medium's 'essence' itself.

\section{Conclusion}

This piece has argued that video-games are historically relevant; they present clear historical arguments through the conscious selection of content while their interactive nature provides them with opportunities to explore the underlying mechanisms of history. As such, censorship is inappropriate in video-games as the process undermines the historical value which it seeks to preserve. I hope to see these sentiments shared, in time, by the historical community and the wider public. Only then, when the nature of video-games is accepted, can the medium's true potential be harnessed. For one, video-game developers are less likely to face censorship, allowing them to explore and wider range of sensitive and controversial issues without fear of repercussions. More broadly, video-game developers, and their clients, will come to see the medium as a completely viable alternative to traditional formats. No longer will 'real history' be delegated solely to academics or articles such as this. Video-games 
can offer - and, indeed, are already - 'real history' through the arguments and themes they espouse, and need not leave serious discussion and ideas to others.

\section{Acknowledgements:}

I thank Dr Pierre Purseigle in providing useful guidance and comments on the piece, while also encouraging me to pursue this area in greater detail. I would also like to thank the peer reviewers, whose comments proved tremendously helpful in improving the article. Finally, I would like to thank my friends and family for being so supportive of my first attempt at academic writing.

\section{References}

\section{Primary Sources}

MachineGames, (2017), Wolfenstein II: The New Colossus, Bethesda Softworks

The Creative Assembly, (2018), Total War Saga: Thrones of Britannia, Sega

Ubisoft Montreal, (2010), Assassins Creed II, Ubisoft

\section{Secondary Sources}

Chapman, A. (2013), 'Is Sid Meier's Civilisation history?', Rethinking History, 17 (3), $317,320,324$

Chapman, A. and J. Linderoth (2015), 'Exploring the limits of play: A case study of representations of Nazism in games', in Brown, A., T. Mortensen and J. Linderoth (eds.), The Dark Side of Game Play; Controversial issues in playful environments, New York: Routledge, pp.143, 149

Clyde, J., H. Hopkins and G. Wilkinson (2012), 'Beyond the historical simulation: Using theories of history to inform scholarly game design', Loading..., 6 (9), 9-11

Elliot, A. and M. Kapell (2013), 'Introduction: To build a past that will "stand the test of time" - discovering historical facts, assembling historical narratives', in Elliot, A. and M. Kapbell (eds.), Playing With The Past; Digital Games and the Simulation of History, New York: Bloomsbury 
Galloway, A. (2006), Gaming; Essays on Algorithmic Culture, Minneapolis: University of Minnesota Press, 102-04

Gamestar (2016), 'Symbol censorship in Germany - Geolock - must it be?', available at https://translate.google.com/translate?

hl=en \&sl=auto \&tl=en \&u=https\%3A\%2F\%2Fwww.gamestar.de\%2Fartikel\%2Fsymb olzensur-in-deutschland-geolock-muss-das-sein\%2C3273534.html\&sandbox=1, accessed 15 July 2018

Good, O. (2017), 'Here's how Wolfenstein 2 censored that Hitler scene for the German release', available at https://www.polygon.com/2017/10/29/16566774/wolfenstein2--censorship-in-germany-video, accessed 14 July 2018

Hußmann, W. and E. Secker (2018), 'USK berücksichtigt bei Altersfreigabe von Spielen künftig Sozialadäquanz', available at https://usk.de/usk-beruecksichtigt-beialtersfreigabe-von-spielen-kuenftig-sozialadaequanz/, accessed on 9 August 2018

Kain, J. (2012), 'Taking back the controller: How Germany's video game rating system curbs freedom of speech', New England Journal of International and Comparative Law, 18 (1)

Miroweski, J. (2015), 'Who's afraid of the swastikas? Nazi symbols in video games', available at https://www.gamepressure.com/e.asp?ID=57, accessed 15 July 2018

Newzoo (2018), 'Top 100 countries/markets by game revenues', available at https://newzoo.com/insights/rankings/top-100-countries-by-game-revenues, accessed 16 July 2018

O'Holleran, J. (2010), 'Blood code: The history and future of video game censorship', Journal on Telecommunications and High Technology Law, 8 (2)

OpiumHerz (2013), 'The worst thing about censorship is [redacted] - 013 - Nazis', available at https://www.destructoid.com/--257400.phtml\#post, accessed 20 July 2018

Oxford Living Dictionaries (n.d.), 'Censorship', available at https://en.oxforddictionaries.com/definition/censorship, accessed 9 September 2018

Rejack, B. (2007), 'Toward a virtual reenactment of history: Video games and the recreation of the past', Rethinking History, 11 (3), 412, 422 
Schwiddessen, S. (2018), 'German Attorney General: Video game with Swastika does not violate the law; constitutes art', available at www.lexology.com/library/detail.aspx?g=dd44ce45-d5cf-4189-a1b6-7bcc7e31605f, accessed 15 July 2018

Ukie (2018), 'The games industry in numbers', available at https://ukie.org.uk/research, accessed 20 June 2018

Uricchio, W. (2005), 'Simulation, history and computer games', in Raessens, J. and J. Goldstein (eds.), Handbook of Computer Game Studies, Cambridge: MIT Press

Verband für Deutschlands Video- und Computerspiele (2018), 'Public Prosecutor will not prosecute “Bundesfighter II Turbo" for using Nazi-symbolism', available at https://vdvc.de/blog/2018/05/08/public-prosecutor-will-not-prosecutebundesfighter-ii-turbo-for-using-nazi-symbolism, accessed 21 July 2018

To cite this paper please use the following details: Piggott, J.A.J. (2019), "The Impact of Censorship on the 'Historical' Video-Game', Reinvention: an International Journal of Undergraduate Research, Volume 12, Issue 2, https://reinventionjournal.org/article/view/360. Date accessed [insert date]. If you cite this article or use it in any teaching or other related activities please let us know by emailing us at Reinventionjournal@warwick.ac.uk. 